\title{
SARS-CoV-2 does not replicate in embryonated hen's eggs or in MDCK cell lines
}

Ian G Barr ${ }^{1,2,3}$, Cleve Rynehart ${ }^{1}$, Paul Whitney ${ }^{1,2}$, Julian Druce 4

1. The WHO Collaborating Centre for Reference and Research on Influenza, The Peter Doherty Institute for Infection and Immunity, Melbourne, VIC, Australia

2. Department of Microbiology and Immunology, The University of Melbourne, The Peter Doherty Institute for Infection and Immunity, Melbourne, VIC, Australia

3. Faculty of Science and Technology, Federation University, Gippsland, VIC, Australia

4. Victorian Infectious Diseases Reference Laboratory, The Peter Doherty Institute for Infection and Immunity, Melbourne, VIC, Australia

Correspondence: Ian G Barr (Ian.Barr@influenzacentre.org)

Citation style for this article:

Barr lan G, Rynehart Cleve, Whitney Paul, Druce Julian. SARS-CoV-2 does not replicate in embryonated hen's eggs or in MDCK cell lines. Euro Surveill. 2020;25(25):pii=2001122. https://doi.org/10.2807/1560-7917.ES.2020.25.25.2001122

The advent of COVID-19, has posed a risk that human respiratory samples containing human influenza viruses may also contain SARS-CoV-2. This potential risk may lead to SARS-CoV-2 contaminating conventional influenza vaccine production platforms as respiratory samples are used to directly inoculate embryonated hen's eggs and continuous cell lines that are used to isolate and produce influenza vaccines. We investigated the ability of these substrates to propagate SARS-CoV-2 and found that neither could support SARS-CoV-2 replication.

The majority of the global production of influenza vaccine is currently performed in embryonated hen's eggs [1] with a growing proportion in mammalian cell lines such as Madin-Darby canine kidney cells (MDCK) [2]. Both of these methods derive their initial viruses from clinical respiratory samples of patients with influenza-like illness (ILI), which are inoculated directly into these substrates [3]. A small proportion of these influenza-positive samples may now be co-infected with severe acute respiratory syndrome coronavirus 2 (SARS-CoV-2) and influenza virus, as reported in a recent study by $\mathrm{Kim}$ et al. 2020 [4]. They found that $0.9 \%$ of samples positive for SARS-CoV-2, from individuals in Northern California, were also positive for influenza virus (with another $5.2 \%$ of SARS-CoV-2 cases co-infected with respiratory syncytial virus (RSV), and $15.5 \%$ with another respiratory pathogen) in a period towards the end of the influenza season (3-25 March 2020) in the United States (US) [4]. During the peak of future influenza seasons, the rate of SARS-CoV-2/ influenza virus co-infections may increase if, as might be expected, SARS-CoV-2 co-circulates with influenza, thereby enhancing the risk of contamination of influenza vaccine seed stocks. Careful screening using sensitive molecular-based methods should reduce the possibility of this occurring, however, there still exists a theoretical risk of viable virus being present, which may compromise candidate influenza vaccine viruses and increase the risk to workers in the influenza vaccine industry and laboratory scientists, who routinely work under a biosafety level (BSL)2 containment and not the higher levels (BSL3 or BSL4) required to amplify SARS-CoV-2 safely.

We investigated if SARS-CoV-2 could be propagated in embryonated hen's eggs or the most used mammalian cell lines that are currently used for propagating influenza viruses (in both the diagnostic laboratory and in vaccine production), MDCK cells and variants of this cell line.

\section{Inoculating and passaging SARS-CoV-2 and influenza viruses on influenza virus substrates}

Briefly we inoculated two different levels (100 median tissue culture infectious dose (TCID 50) and 1,000 TCID50) of Vero (African green monkey kidney cells; ATCC CCL-81) cell-grown SARS-CoV-2 in $100 \mu \mathrm{L}$ of phosphate buffered saline (PBS) containing $1.45 \mathrm{mg} / \mathrm{mL}$ of neomycin sulphate (Pharmacia \& Upjohn, Peapack, New Jersey, US) and $0.25 \mathrm{mg} / \mathrm{mL}$ of polymyxin B sulphate (Xellia Pharmaceuticals, Copenhagen, Denmark) into the amniotic cavity or the allantoic cavity of three 15-days-old or three 11-days-old, embryonated hen's eggs (vaccine certified) respectively and incubated them for 3 days at $35^{\circ} \mathrm{C}$. Fluids were harvested from the eggs and pooled according to their inoculum dose and site, then re-passaged a further two times by reinoculating $100 \mu \mathrm{L}$ of a 1:2 dilution of fluid in PBS and antibiotics into the same sites into three eggs/site/ inoculum dose and harvesting fluids (but not pooling) after 3 days at $35^{\circ} \mathrm{C}$. This process mimics influenza 
Quantification of SARS-CoV-2 a and influenza ${ }^{\mathrm{b}}$ viruses' RNA after passages into embryonated hen's eggs and Vero cells

\begin{tabular}{|c|c|c|c|c|c|}
\hline Virus & $\begin{array}{l}\text { Route of } \\
\text { inoculation }\end{array}$ & SARS-CoV-2 TCID $_{50}$ (Ct value) & $\begin{array}{c}\text { Passage } 1 \\
\text { Ct value }\end{array}$ & $\begin{array}{c}\text { Passage } 2 \\
\text { Ct value }\end{array}$ & $\begin{array}{c}\text { Passage } 3 \\
\text { Ct value }\end{array}$ \\
\hline \multirow{17}{*}{ SARS-CoV-2 } & \multicolumn{5}{|l|}{ Amniotic } \\
\hline & E1 & $100(28)$ & \multirow{3}{*}{$38^{c}$} & ND & ND \\
\hline & E2 & $100(28)$ & & ND & ND \\
\hline & E3 & $100(28)$ & & ND & ND \\
\hline & E1 & $1,000(25)$ & \multirow{3}{*}{$36^{c}$} & ND & ND \\
\hline & E2 & $1,000(25)$ & & ND & ND \\
\hline & E3 & $1,000(25)$ & & ND & ND \\
\hline & \multicolumn{5}{|l|}{ Allantoic } \\
\hline & $\mathrm{E}_{1}$ & $100(28)$ & \multirow{3}{*}{$37^{c}$} & ND & ND \\
\hline & E2 & $100(28)$ & & ND & ND \\
\hline & E3 & $100(28)$ & & ND & ND \\
\hline & E1 & $1,000(25)$ & \multirow{3}{*}{$33^{c}$} & ND & ND \\
\hline & E2 & $1,000(25)$ & & ND & ND \\
\hline & E3 & $1,000(25)$ & & ND & ND \\
\hline & \multicolumn{5}{|l|}{ Vero cells } \\
\hline & VC & $100(28)$ & 17 & NA & NA \\
\hline & VC & $1,000(25)$ & 15 & NA & NA \\
\hline Influenza & \multicolumn{5}{|l|}{ Allantoic } \\
\hline - $\quad B /$ Victoria/2110/2019 & $\mathrm{E}$ & $N A(26)^{d}$ & 11 & NA & NA \\
\hline - $\mathrm{B} /$ Victoria/2113/2019 & $\mathrm{E}$ & $N A(27)^{d}$ & 10 & NA & NA \\
\hline
\end{tabular}

Ct: cycle threshold; E: egg; NA: not applicable/not done; ND: not detected; SARS-CoV-2: severe acute respiratory syndrome coronavirus 2; $T_{C I D_{50}}$ : median tissue culture infectious dose; VC: Vero cell.

${ }^{a}$ Quantification of SARS-CoV-2 RNA after each passage in eggs and Vero cells was assessed with a real-time RT-PCR assay targeting the RNAdependent RNA polymerase (RdRp) gene.

${ }^{b}$ Quantification of influenza virus RNA after one egg passage was assessed with a previously described real-time RT-PCR assay [9].

${ }^{c}$ At passage 1, E1, E2,E3 harvests were pooled and then inoculated into three separate eggs at passage 2 then respectively carried onto passage 3.

${ }^{d}$ Allantoic isolate initially diluted $10^{-6}$

virus isolation from clinical samples (amniotic inoculation) and virus growth in vaccine production (allantoic inoculation) using the embryonated hen's egg platform. As a control, embryonated hen's eggs from the same batch of eggs were separately inoculated allantoically with a $1 \times 106$ dilution of a previous egg passage of $\mathrm{B} /$ Victoria/2110/2019 or B/Victoria/2113/2019 (both $B /$ Victoria lineage viruses) for a single passage.

For attempted propagation in mammalian cells, $5 \times 10^{4}$, $5 \times 10^{3}$ or $5 \times 10^{2} \mathrm{TCID}_{50}$ inoculums of SARS-CoV-2 derived from infection of Vero cells were applied in Dulbecco's Modified Eagle Minimum Essential media (DMEM) to T25 flasks (Corning cell culture flasks, surface area
$25 \mathrm{~cm}^{2}$, canted neck, cap (vented); Sigma-Aldrich, Sydney, Australia) containing confluent cell monolayers of either regular MDCK cells (ATCC CCL-34), MDCKSIAT-1 [5], MDCK-TMPRSS2 [6], MDCK-hCK [7] or Vero cells and after $60 \mathrm{~min}$ the inoculum was removed and media containing $4 \mu \mathrm{g} / \mathrm{mL}$ trypsin (Sigma-Aldrich) was added and cells were incubated at $37^{\circ} \mathrm{C}$ for 6 days (as previously described [8]). Subsequently $100 \mu \mathrm{L}$ samples from this first passage were inoculated onto fresh cell monolayers in T25 flasks as detailed above and incubated at $35^{\circ} \mathrm{C}$ for a further 6 days. As a control, another set of flasks containing these same cell lines were separately inoculated with human influenza virus isolates (A/Victoria/13/2020 (H1N1pdmog) or B/ 
TABLE 2

Quantification of SARS-CoV-2 ${ }^{\mathrm{a}} \mathrm{RNA}$ after passages into various MDCK cell lines and Vero cells

\begin{tabular}{|l|c|c|c|}
\multirow{2}{*}{ Cell line } & \multicolumn{2}{|c|}{ Passage 1} & Passage 2 \\
\cline { 2 - 4 } & $\begin{array}{c}\text { SARS-CoV-2 } \\
\text { inoculum TCID }\end{array}$ & $\begin{array}{c}\text { Flask } 1 ; \text { flask } \\
2 \text { Ct values }\end{array}$ & $\begin{array}{c}\text { Pooled flasks } \\
1+2 \text { Ct value }\end{array}$ \\
\hline \multirow{3}{*}{ MDCK } & $5 \times 10^{4}$ & $27 ; 26$ & 37 \\
\cline { 2 - 4 } & $5 \times 10^{3}$ & $29 ; 29$ & 39 \\
\hline \multirow{3}{*}{ MDCK-SIAT-1 } & $5 \times 10^{4}$ & $26 ; 25$ & 37 \\
\cline { 2 - 4 } & $5 \times 10^{3}$ & $29 ; 28$ & 37 \\
\hline \multirow{3}{*}{ MDCK-TMPRSS2 } & $5 \times 10^{4}$ & $26 ; 27$ & 37 \\
\cline { 2 - 4 } & $5 \times 10^{3}$ & $30 ; 30$ & 37 \\
\hline \multirow{3}{*}{ MDCK-hCK } & $5 \times 10^{4}$ & $\mathrm{ND} ; 26$ & 37 \\
\cline { 2 - 4 } & $5 \times 10^{3}$ & $28 ; 35$ & 37 \\
\hline \multirow{3}{*}{ Vero } & $5 \times 10^{4}$ & 14 & NA \\
\cline { 2 - 5 } & $5 \times 10^{3}$ & 15 & NA \\
\cline { 2 - 5 } & $5 \times 10^{2}$ & 15 & 12 \\
\hline
\end{tabular}

Ct: cycle threshold; MDCK: Madin-Darby canine kidney cells; NA: not applicable/not done; ND: not detected; SARS-CoV-2: severe acute respiratory syndrome coronavirus $2 ; T_{C}$ : median tissue culture infectious dose.

${ }^{a}$ Quantification of SARS-CoV-2 RNA after each passage in MDCK cell lines and Vero cells was assessed with a real-time RT-PCR assay targeting the RNA-dependent RNA polymerase (RdRp) gene.

Victoria/2117/2019 (B/Victoria-lineage)) with $200 \mu \mathrm{L}$ of a $1 \times 10^{3}$ dilution of an existing isolate, using the same method as above, for a single passage.

\section{Assessing SARS-CoV-2 and influenza viruses' propagation on influenza virus substrates}

Samples from the egg-passaged and mammalian cellpassaged SARS-CoV-2 samples were examined for propagation of SARS-CoV-2, visually inspected for embryo viability (eggs), for cytopathogenic effects CPE (cells), and by real-time RT-PCR (both cells and eggs) targeting the RNA-dependent RNA polymerase (RdRp) gene of SARS-CoV-2 with cycle thresholds (Ct) rounded up or down to the nearest integer. Briefly, for cell samples, $200 \mu \mathrm{L}$ were subjected to RNA extraction using the QIAmp 96 Virus QIAcube HT kit (Qiagen, Hilden, Germany) and the RNA was eluted in $60 \mu \mathrm{L}$, while for egg samples, RNA was extracted from $140 \mu \mathrm{L}$ with QIAamp mini-Viral RNA columns (Qiagen) and eluted in $60 \mu \mathrm{L}$. Reverse transcription and real-time PCR were performed as previously described [8] using an Applied Biosystems Fast Real Time PCR machine (Applied Biosystems, Foster City, California, US). Influenza RNA was detected as previously described [9].
TABLE 3

Quantification of influenza ${ }^{\text {a }}$ viruses' RNA after passage into various MDCK cell lines ${ }^{\mathrm{b}}$ and Vero cells

\begin{tabular}{|c|c|c|}
\hline Cell line & Virus & $\begin{array}{c}\text { Passage } 1 \\
\text { Ct value }\end{array}$ \\
\hline \multirow{2}{*}{ MDCK } & $\mathrm{A} /$ Victoria $/ 13 / 2020^{\mathrm{C}}$ & 10 \\
\hline & $\mathrm{B} /$ Victoria/2117/2019 & 12 \\
\hline \multirow{2}{*}{ MDCK-SIAT-1 } & $\mathrm{A} /$ Victoria/13/2020 & 9 \\
\hline & B/Victoria/2117/2019 & 11 \\
\hline \multirow{2}{*}{ MDCK-TMPRSS2 } & $\mathrm{A} /$ Victoria/13/2020 & 12 \\
\hline & B/Victoria/2117/2019 & 14 \\
\hline \multirow{2}{*}{ MDCK-hCK } & A/Victoria/13/2020 & 11 \\
\hline & B/Victoria/2117/2019 & 13 \\
\hline \multirow{2}{*}{ Vero } & $\mathrm{A} /$ Victoria/13/2020 & 29 \\
\hline & $\mathrm{B} /$ Victoria/2117/2019 & 36 \\
\hline
\end{tabular}

Ct: cycle threshold; MDCK: Madin-Darby canine kidney cells.

${ }^{a}$ Quantification of influenza virus RNA after one passage in cells was assessed with a previously described real-time RT-PCR assay [9].

b Same cell lines as in Table 2

${ }^{c} \mathrm{An} A\left(\mathrm{H}_{1} \mathrm{~N}_{1}\right)$ pdmog virus - initial inoculum diluted $1 \times 10^{-3} ; \mathrm{Ct}=25$.

${ }^{d} \mathrm{~A} B$ /Victoria-lineage virus - initial inoculum diluted $1 \times 10^{-3}$; $\mathrm{Ct}=29$.

\section{Ethical statement}

All experiments with SARS-CoV-2 were conducted in BSL-3 facilities and the use of embryonated hen's eggs was approved by the University of Melbourne Animal Ethics Committee (2015136.1).

\section{Effects of inoculating SARS-CoV-2 and influenza viruses on hen's eggs and Vero cells}

Table 1 shows the results from the egg-inoculations. The initial inoculum of SARS-CoV-2 had $\mathrm{Ct}$ values of 28 for $100 \mathrm{TCID}_{50}$ and $251,000 \mathrm{TCID}_{50}$. Following the first amniotic passage into three individual eggs, the pooled amniotic fluids had a $\mathrm{Ct}$ of 38 for the 100 TCID $_{50}$ inoculum and 36 for the 1,000 TCID $_{50}$ inoculum, and allantoically inoculated eggs gave Cts of 37 and 33 respectively for allantoic fluids. These $\mathrm{Ct}$ values continued to increase to undetectable levels ( $\mathrm{Ct}$ >40) upon further passaging for both sites of inoculation. In contrast when the $100 \mathrm{TCID}_{50}$ and the $1,000 \mathrm{TCID}_{50}$ were inoculated into Vero cells after 3 days at $37^{\circ} \mathrm{C}$ they gave reduced $\mathrm{Ct}$ values of 17 and 15 respectively, indicating a high level of replication had occurred. No effect on embryo viability was detected following inoculation with SARS-CoV-2. Eggs inoculated separately with two influenza B viruses (initial influenza B Cts of 26 and 27) both replicated to high levels as indicated by the highly reduced influenza $B$ Cts of 11 (for $B / V i c t o r i a / 2110 / 2019$ ) and 10 (for B/Victoria/2113/2019), after a single 
passage (Table 1). Eggs inoculated with buffer alone had no detectable SARS-CoV-2 RdRp signal.

\section{Effects of inoculating SARS-CoV-2 and influenza viruses on MDCK cell lines and Vero cells}

The results testing SARS-CoV-2 propagation in mammalian cell lines are shown in Table 2. At the first passage there was residual SARS-CoV-2 detected in most MDCK cell lines ( $\mathrm{Ct}$ values ranged from not detected down to 25, with no (PE) while the Vero cells showed lower Cts of 15, 15, 14 in T25 culture flasks (and extensive CPE) when inoculated with $5 \times 10^{4}, 5 \times 10^{3}$, $5 \times 10^{2} \mathrm{TCID}_{50}$ respectively, 6 days after inoculation, indicating high levels of SARS-CoV-2 replication. When a $100 \mu \mathrm{L}$ sample of each MDCK cell line from passage 1 was applied to new cells (of the same type), this second passage showed no CPE or decrease in Ct values, producing signal levels equivalent to background (Cts: 37-39), indicating that no SARS-CoV-2 replication had occurred. In contrast when $100 \mu \mathrm{L}$ from passage 1 in Vero cells (Day6; originally inoculated with $5 \times 10^{2} \mathrm{TCID}_{50}$ SARS-(oV-2) was applied to fresh Vero cells, this resulted in a $\mathrm{Ct}$ of 12 , again indicating high levels of replication at this second passage (Table 2).

As a control, MDCK cell lines inoculated separately with either an influenza A or B virus (initial influenza A and B Cts of 25 and 29 respectively) both replicated to high levels as indicted by the highly reduced $\mathrm{Cts}$ (influenza A Cts of 9-12 and influenza B Cts of 11-14 respectively) after a single passage, however, Vero cells showed little signs of influenza replication (Table 3). No CPE was detected in any of the MDCK cell lines inoculated with SARS-CoV-2. Uninfected cell lines all showed no detectable SARS-CoV-2 RdRp signal or CPE.

\section{Discussion}

These results are in line with a previous report [10] that showed that the closely related SARS-CoV-1 (previously known as SARS or SARS-CoV) did not replicate in 9- or 13-days-old embryonated chicken eggs or 17-days-old embryonated turkey eggs when inoculated allantoically. Furthermore, SARS-CoV-1 given by an intra-tracheal challenge to a range of avian species (including geese, ducks, chickens, turkeys and quails), showed only residual levels of RT-PCR virus specific product. There was no infectious virus isolated from inoculated birds or any specific histological lesions from a range of tissues examined and plasma samples showed no seroconversion to SARS-CoV-1, indicating that this virus did not infect these species [9]. In studies on permissiveness of coronavirus to standard MDCK cells, Kaye et al. 2006 [11] showed that SARSCoV-1 did not replicate as measured by CPE, indirect fluorescence antibody (IDFA) or quantitative RT-PCR, but did replicate in a wide range of mammalian continuous cell lines (derived from kidney epithelium, kidney fibroblasts and liver cells) including Vero/ VeroE6 cells. This was supported by a study of the lack of growth of a seasonal coronavirus (E229) in the
MDCK-33016 cells developed for cell-based influenza vaccine production [12]. Even when MDCK cells were engineered to increase the infectivity or yield for influenza viruses (SIAT-1, TMPRSS2, hCK), no replication of SARS-CoV-2 was observed in this present study, unlike when transmembrane serine protease 2 (TMPRSS2) was expressed in VeroE6 cells in another study, which resulted in enhanced replication of SARS-CoV-2 compared with VeroE6 or standard Vero cells [13]. All of the MDCK cell lines tested in the present study, efficiently propagated influenza $A$ and influenza $B$ isolates, and embryonated hen's eggs efficiently propagated influenza $B$ viruses when inoculated allantoically.

\section{Conclusions}

The studies described above give us confidence that even if a clinical sample, containing both human influenza and SARS-CoV-2, was inoculated into substrates used to prepare seeds for influenza vaccine production (embryonated chicken eggs or MDCK-based cell lines), SARS-CoV-2 would be unlikely to be propagated and would be undetectable after a small number of passages. This finding will reassure influenza vaccine production staff and laboratory scientists who might be concerned about potential exposure to SARS-CoV-2 and also suggests that loss of potentially important influenza candidate vaccine viruses or final vaccine lots due to SARS-CoV-2 contamination is unlikely.

\section{Acknowledgments}

The authors would like to thank Rajeev Rudraraju and Francesca Mordant for provision of SARS-CoV-2 virus stock and Vero cells. The Melbourne WHO Collaborating Centre for Reference and Research on Influenza is supported by the Australian Government Department of Health.

Conflict of interest

None declared.

Authors' contributions

IGB conceived the study and wrote the paper. CR, PW and JD conducted the study and edited the manuscript.

\section{References}

1. Trombetta CM, Marchi S, Manini I, Lazzeri G, Montomoli E. Challenges in the development of egg-independent vaccines for influenza. Expert Rev Vaccines. 2019;18(7):737-50. https:// doi.org/10.1080/14760584.2019.1639503 PMID: 31265333

2. Hegde NR. Cell culture-based influenza vaccines: A necessary and indispensable investment for the future. Hum Vaccin Immunother. 2015;11(5):1223-34. https://doi.org/10.1080/2164 5515.2015.1016666 PMID: 25875691

3. Gregersen JP. A quantitative risk assessment of exposure to adventitious agents in a cell culture-derived subunit influenza vaccine. Vaccine. 2008;26(26):3332-40. https://doi. org/10.1016/j.vaccine.2008.03.075 PMID: 18485545

4. Kim D, Quinn J, Pinsky B, Shah NH, Brown I. Rates of Coinfection Between SARS-CoV-2 and Other Respiratory Pathogens. JAMA. 2020;323(20):2085. https://doi. org/10.1001/jama.2020.6266 PMID: 32293646

5. Matrosovich M, Matrosovich T, Carr J, Roberts NA, Klenk HD. Overexpression of the alpha-2,6-sialyltransferase in MDCK 
cells increases influenza virus sensitivity to neuraminidase inhibitors. J Virol. 2003;77(15):8418-25. https://doi. org/10.1128/JVI.77.15.8418-8425.2003 PMID: 12857911

6. Lee JM, Huddleston J, Doud MB, Hooper KA, Wu NC, Bedford $T$, et al. Deep mutational scanning of hemagglutinin helps predict evolutionary fates of human $\mathrm{H}_{3} \mathrm{~N}_{2}$ influenza variants. Proc Natl Acad Sci USA. 2018;115(35):E8276-85. https://doi. org/10.1073/pnas.1806133115 PMID: 30104379

7. Takada K, Kawakami C, Fan S, Chiba S, Zhong G, Gu C, et al. A humanized MDCK cell line for the efficient isolation and propagation of human influenza viruses. Nat Microbiol. 2019;4(8):1268-73. https://doi.org/10.1038/s41564-019-04336 PMID: 31036910

8. Caly L, Druce J, Roberts J, Bond K, Tran T, Kostecki R, et al. Isolation and rapid sharing of the 2019 novel coronavirus (SARS-CoV-2) from the first patient diagnosed with COVID-19 in Australia. Med J Aust. 2020;212(10):459-62. https://doi. org/10.5694/mja2.50569 PMID: 32237278

9. Price $\mathrm{OH}$, Spirason N, Rynehart C, Brown SK, Todd A, Peck $\mathrm{H}$, et al. Report on influenza viruses received and tested by the Melbourne WHO Collaborating Centre for Reference and Research on Influenza in 2018. Commun Dis Intell (2018). 2020;44:44. https://doi.org/10.33321/cdi.2020.44.16 PMID: 32178606

10. Swayne DE, Suarez DL, Spackman E, Tumpey TM, Beck JR, Erdman D, et al. Domestic poultry and SARS coronavirus, southern China. Emerg Infect Dis. 2004;10(5):914-6. https:// doi.org/10.3201/eid1005.030827 PMID: 15200830

11. Kaye M, Druce J, Tran T, Kostecki R, Chibo D, Morris J, et al. SARS-associated coronavirus replication in cell lines. Emerg Infect Dis. 2006;12(1):128-33. https://doi.org/10.3201/ eid1201.050496 PMID: 16494729

12. Gregersen JP. A quantitative risk assessment of exposure to adventitious agents in a cell culture-derived subunit influenza vaccine. Vaccine. 2008;26(26):3332-40. https://doi. org/10.1016/j.vaccine.2008.03.075 PMID: 18485545

13. Matsuyama S, Nao N, Shirato K, Kawase M, Saito S, Takayama I, et al. Enhanced isolation of SARS-CoV-2 by TMPRSS2expressing cells. Proc Natl Acad Sci USA. 2020;117(13):7001-3. https://doi.org/10.1073/pnas.2002589117 PMID: 32165541

\section{License, supplementary material and copyright}

This is an open-access article distributed under the terms of the Creative Commons Attribution (CC BY 4.0) Licence. You may share and adapt the material, but must give appropriate credit to the source, provide a link to the licence and indicate if changes were made.

Any supplementary material referenced in the article can be found in the online version.

This article is copyright of the authors or their affiliated institutions, 2020. 